\title{
Algorithm for Fault Location and Classification on Parallel Transmission Line using Wavelet based on Clarke's Transformation
}

\author{
Makmur Saini ${ }^{1}$, A. A. Mohd Zin ${ }^{2}$, M. W. Mustafa ${ }^{3}$, A. R. Sultan ${ }^{4}$, Rusdi Nur ${ }^{5}$ \\ ${ }^{1,5}$ Department of Mechanical Engineering, Politeknik Negeri Ujung Pandang, Indonesia \\ ${ }^{2,3}$ Department of Electrical Engineering, Universiti Teknologi Malaysia, Malaysia \\ ${ }^{4}$ Department of Electrical Engineering, Politeknik Negeri Ujung Pandang, Indonesia
}

\begin{tabular}{l}
\hline \hline Article Info \\
\hline Article history: \\
Received Nov 2, 2017 \\
Revised Mar 10, 2018 \\
Accepted Mar 16, 2018 \\
\hline
\end{tabular}

\section{Keyword:}

Clarke's transformation

Fault detection

Fault location

Transmission parallel line

Wavelet transformation

\begin{abstract}
This paper proposed a new algorithm for fault location and classification using wavelet based on Clarke's transformation to obtain the fault current. This novel method of fault current approach is studied by comparing the use of the glide path of the fault voltage. The current alpha and beta (Current Mode) were used to transform the signal using discrete wavelet transform (DWT). The fault location was determined by using the Clarke's transformation, and then turned into a wavelet, which was very precise and thorough. The most accurate was the mother wavelet Db4 which had the fastest time and smallest error detection when compared with the other wavelet mothers. In this study, the Clarke's transformation is also compared with the Karenbauer's, which has produced results with similar error percentage. The simulation results using PSCAD / EMTDC software showed that the proposed algorithm could distinguish internal and external faults to get the current signal in the transformation of a signal fault.
\end{abstract}

Copyright $@ 2018$ Institute of Advanced Engineering and Science. All rights reserved.

\section{Corresponding Author:}

Makmur Saini,

Departement of Mechanical Engineering,

Politeknik Negeri Ujung Pandang,

Jalan Perintis Kemerdekaan Km. 10, Makassar 90245, Indonesia.

Email: makmur.saini@poliupg.ac.id

\section{INTRODUCTION}

Currently, the parallel transmission networks are widely used in the electrical power systems. Therefore, a fast and reliable protection is very much needed in such aspects as rapid fault detection and accurate estimation of the location fault will reduce errors, and assist in the maintenance and restoration services to improve the continuity and reliability of electric supply. Therefore, parallel transmission lines require more special consideration in comparison with a single transmission line, due to the effect of mutual coupling on the parallel transmission line. It also must conform to the standard IEEE.STD.114 2004 [1]. One main advantage of parallel transmission is the availability of the transmission lines during and after the fault.

Fault location problems in the parallel transmission lines have been widely researched. Many diagnostic approaches have been proposed in the literature, including fault location based on the amount of electricity, which includes one-terminal method [2], [3], two-terminal method [4], [5], traveling wave analysis method [6], [7], resistance measurement method [8], and the determination of fault location estimation using wavelet transform [9].

This paper proposed discrete wavelet transformation using the Clarke's transformation to determine the fault location estimation and classification on the parallel transmission lines. This study presents a different approach, which is based on the Clarke's transformation known as alpha-beta transformation, which 
is a transformation of a three-phase system into a two-phase system [10], [11], where after the result, the Clarke's transformation is then transformed into discrete wavelet transform.

Wavelet transform is an effective tool in analyzing the transient current and signal associated with faults, both in frequency and in the time-domain [12], [13] and is ideal for dealing with non-stationary signal. This can improve the accuracy, reliability of the detection and classification of power quality disturbance [14], and features can be applied to determine the fault location estimation [15].

The proposed approach combines the decomposition of electromagnetic wave propagation modes, using the Clarke's transformation of signal processing, given by the discrete wavelet transformation based on the maximum signal amplitude (WTC) ${ }^{2}$ to determine the intrusion time. This work made extensive use of the simulation software PSCAD/EMTDC [16] which resulted in the fault of the simulation of the transient signal transmission line parallel to the number of data points $\left(10^{5}\right)$. For one kind of fault, these data were then transferred to MATLAB with the help of Clarke's transformation to convert the three-phase signal into alpha and beta signals. The signals were then transformed into several mother wavelets [17] such as Db4, Sym4, Coil4 and Db8 which were manipulated for comparison in terms of time and the distance estimation fault in the parallel transmission line.

\section{BASIC PRINCIPLE OF CLARKE'S AND WAVELET TRANSFORMATION}

\subsection{Clarke's Transformation}

Clarke's Transformation $(\alpha \beta 0)$ is a useful analytical approach to complement symmetry components $(0,1,2)$. Clarke's transformation can overcome some symmetry component drawbacks such as the calculation of the circuit transient phenomena. Clarke's Transformation $(\alpha \beta 0)$ is the transformation method that contains the elements of a 3 x 3 matrix, containing matrix element in the form of real, whereas the symmetry component contains matrix components in the form of real and complex numbers. A three-phase current which has a digital representation is assumed to have the form [18], [19]. Therefore, the above components can be formed into a matrix [20]

$$
\mathrm{i}_{\text {mode }}=\mathrm{i}_{\alpha \beta 0}=C i_{a b c}=\frac{2}{3}\left[\begin{array}{ccc}
1 & -\frac{1}{2} & -\frac{1}{2} \\
0 & \frac{\sqrt{3}}{2} & -\frac{\sqrt{3}}{2} \\
\frac{1}{2} & \frac{1}{2} & \frac{1}{2}
\end{array}\right] x\left[\begin{array}{c}
i_{a}(n) \\
i_{b}(n) \\
i_{c}(n)
\end{array}\right]
$$

where $\mathrm{C}$ is the well-known transformation introduced by Edith Clarke [21].

\subsection{Fault Characterization in Clarke's Transformation}

\subsubsection{Single Line of Ground Fault Phase $A$ to $G$}

A suppose for a line to ground fault (AG), assuming the grounding resistance is zero, then the instantaneous boundary conditions will be:

$$
I_{B}=I_{C}=0 \text { and } V_{A}=0
$$

Then, the boundary condition instantaneous will be:

$$
\left[\begin{array}{l}
I_{\alpha} \\
I_{\beta} \\
I_{0} \\
- \\
I_{\gamma}
\end{array}\right]=\left[\begin{array}{cc}
-2 / 3 & I_{A} \\
0 & \\
-1 / 3 & I_{A} \\
- & \\
-2 / 3 & I_{A}
\end{array}\right]
$$

\subsubsection{Line to Line Fault in Phase A-B}

A suppose for the line to line fault $(A B)$, assuming the grounding resistance is zero, then the instantaneous boundary conditions will be:

$$
I_{C}=0, I_{A}=-I_{B} \quad \text { and } V_{A}=V_{B}
$$

Then, the boundary condition instantaneous will be: 


$$
\left[\begin{array}{c}
I_{\alpha} \\
I_{\beta} \\
I_{0} \\
- \\
I_{\gamma}
\end{array}\right]=\left[\begin{array}{ccc}
I_{a} & \\
-1 / 3 \sqrt{3} & I_{b} \\
0 \\
- & \\
-I_{a}-1 / 3 \sqrt{3} & I_{b}
\end{array}\right]
$$

\subsubsection{Line to Line to ground Fault in Phase $A B$ to $G$}

A suppose line to line to ground fault $(\mathrm{ABG})$, assuming the grounding resistance is zero, then the instantaneous boundary conditions will be:

$$
I_{C}=0, I_{A}=I_{B} \quad \text { and } V_{A}=V_{B}=0
$$

Then, the boundary condition instantaneous will be:

$$
\left[\begin{array}{c}
I_{\alpha} \\
I_{\beta} \\
I_{0} \\
- \\
I_{\gamma}
\end{array}\right]=\left[\begin{array}{c}
2 / 3 I_{a}-1 / 3 I_{b} \\
1 / 3 \sqrt{3} I_{b} \\
1 / 3 I_{a}+1 / 3 I_{b} \\
- \\
-2 / 3 I_{a}+1 / 3 I_{b}+1 / 3 \sqrt{3} I_{b}
\end{array}\right]
$$

\subsubsection{Three Phase Fault in Phase ABC}

A suppose for three phase fault $(\mathrm{ABC})$, assuming the grounding resistance is zero, then the instantaneous boundary conditions will be:

$$
I_{a}+I_{b}+I_{c}=0 \text { and } \quad V_{a}+V_{b}+V_{c}=0
$$

Then, the boundary condition instantaneous will be:

$$
\left[\begin{array}{c}
I_{\alpha} \\
I_{\beta} \\
I_{0} \\
- \\
I_{\gamma}
\end{array}\right]=\left[\begin{array}{c}
\frac{2}{3} I_{a}-\frac{1}{3} I_{b}-\frac{1}{3} I_{c} \\
\frac{1}{3} \sqrt{3} I_{b}-\frac{1}{3} \sqrt{3} I_{c} \\
0 \\
-\frac{2}{3} I_{a}+\frac{1}{3} I_{b}-\frac{1}{3} \sqrt{3} I_{b}+\frac{1}{3} I_{c}+\frac{1}{3} \sqrt{3} I_{c}
\end{array}\right]
$$

Based on the above analysis, the characteristics of various faults based on Clarke's transformation $\alpha$ - Modal, $\beta$ - Modal and modal $\gamma$ can be proposed.

\subsection{Wavelet Transformation}

Wavelet transformation is the decomposition of a signal by a function $\varphi_{a(t)}$ which is deleted and translated by the so-called mother wavelet. The function of the mother wavelet can be written as follows [22], [23]:

$$
\varphi_{a b(t)}=\frac{1}{\sqrt{a}} \varphi\left(\frac{t-b}{a}\right)
$$

Where $a$ is the dilation parameter ( $a \varepsilon$ Real ) and $b$ is a translation parameter ( $b \varepsilon$ Real ), parameter $a$ indicates the width of the wavelet curve, when the value of a wider magnified wavelet curve is diminished as the curve gets smaller, while the wavelet parameter curve $b$ shows the localization of wavelet centered at $t=b$. The detection of the discrete wavelet transformed (DWT) fault is required so that the equation becomes [24], [25]

$$
\varphi_{a b(t)}=2^{j / 2} \varphi\left(2^{j}(a-b)\right), j \cdot k \in Z
$$

Variables $j$ and $k$ are integers that scale the shifts of the mother wavelet function, to produce types of mother wavelet such as Syms and Haar wavelets. The width of a wavelet is shown by the scale $a$, and the position is indicated by the wavelet scale $b$. 
Discrete Wavelet Transformations (DWT) are methods used to decompose the input signal, and the signal is analyzed by giving treatment to the wavelet coefficients. The decomposition process involves two filters, which are low-pass filter and a high-pass filter [26]. This is achieved by successive high pass and low pass filtering of the time domain signal and is defined by the following equation:

$$
\begin{aligned}
& \delta_{\text {high }}[k]=\sum_{n} X[n] \cdot g[2 k-n] \\
& \delta_{\text {low }}[k]=\sum_{n} X[n] \cdot h[2 k-n]
\end{aligned}
$$

where $\delta_{\text {high }}[k]=$ output high-pass filter and $\delta_{\text {low }}[k]=$ output low-pass filter.

The signal is first passed through the high-pass filter and low pass filter, and then half of each output is taken as sampling, down through the sampling operation, the signal of desired frequency component can be obtained from the recurring decompositions as shown by Figure 1 [27].

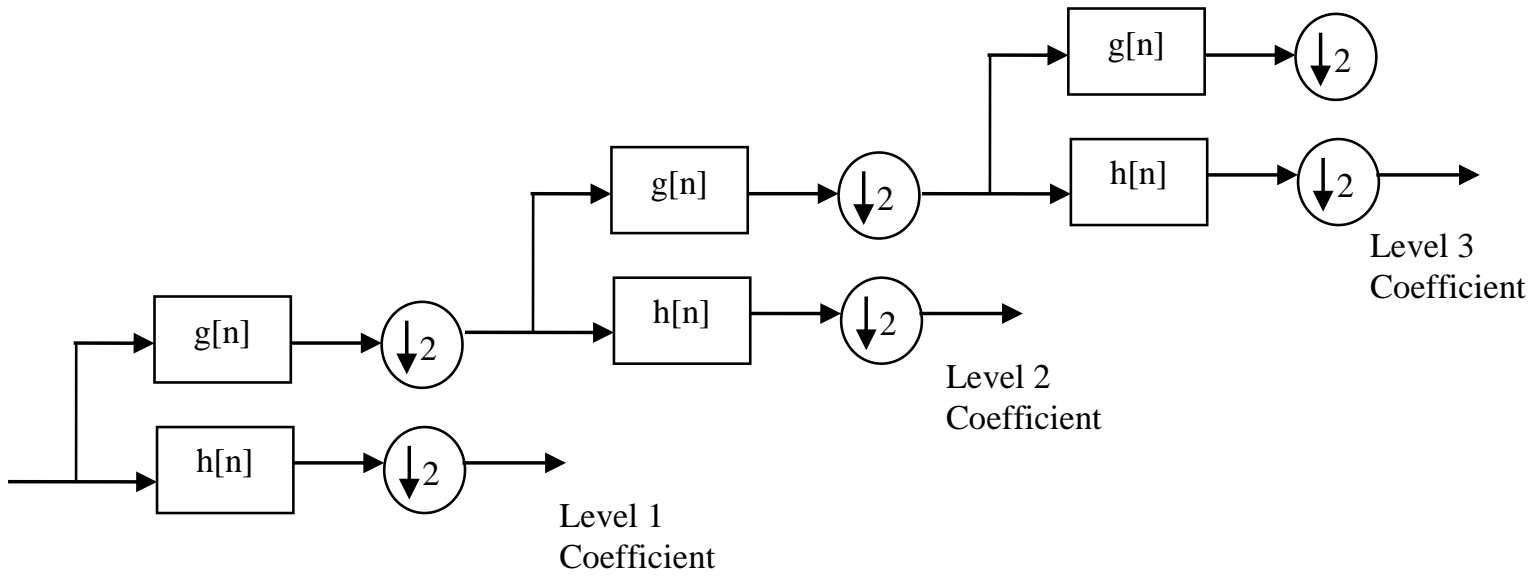

Figure 1. The process decomposition of discrete wavelet transform

This is called a decomposition first level process in the frequency range of $250-500 \mathrm{kHz}$. The output from the low-pass filter is used as the input of the next decomposition second level, with a frequency range of $125-250 \mathrm{kHz}$. This process is repeated again until it reaches the third level of decomposition with a frequency of $62.5-125 \mathrm{kHz}$, and so forth, according to the level desired. In this study, it is chosen to reach level 4, with a frequency range of $31.25-62.5 \mathrm{kHz}$ and a level 8 with frequency range of $7.8125-15.625 \mathrm{kHz}$ [28].

The combination of the output from the high-pass filter and low-pass filter output is called Coefficient Wavelet transformed (CWT), which contains information on the results that have been compressed and transformed. In this study, the high pass filter and low-pass filter are coupled and becoming a Quadrature Mirror Filter (QMF), in which the couples meet the following [29] equation:

$$
h[n]=(-1)^{n} g[L+1-n]
$$

where $h[n]=$ high-pass filter, $g[n]=$ low-pass filter, $\mathrm{L}=$ length of each filter. Successful to the down sampling operation that removes redundant information signal, wavelet transform has become one of the most reliable and accurate composition methods [30].

\section{THE PROPOSED ALGORITHM}

In this study, the simulations were performed using PSCAD, and the simulation results were obtained from the fault current signal.

The steps performed in this study were:

a. Finding the input to the Clarke's transformation and wavelet transform. The signal flow of PSCAD was then converted into $\mathrm{m}$. files $(* . \mathrm{M})$ and then converted into mat. Files (*mat) with a sampling rate of $\left(10^{5}\right)$ and frequency dependent of $0.5 \mathrm{~Hz}-1 \mathrm{MHz}$. 
b. Determining the data stream interference, where the signal was transformed by using the Clarke's transformation to convert the transient signals into the basic current mode signal in using Equation (1).

c. Transforming the mode current signals again by using DWT and WTC, which were the generated coefficients, and then squared to be $(W T C)^{2}$ in order to obtain the maximum signal amplitude to determine the time of the interruption [31], [32].

d. Processing the ground mode and aerial mode and $(W T C)^{2}$ using the Bewley Lattice diagram [32], [33] of the initial wave to determine the fault location and detection.

e. Adding the magnitude of the current gamma to make the fault classification algorithm which then became modal $I_{\gamma}$ that can be proposed. While the magnitude of the current gamma of each different types of fault can be seen in Table 1 .

$$
I_{\gamma}=-2 / 3 I_{a}+1 / 3(1+\sqrt{3}) I_{b}+1 / 3(1-\sqrt{3}) I_{c}
$$

f. Determining whether the internal fault in both Circuit 1 or Circuit 2 and external fault using the following equation:

$$
\begin{aligned}
& \text { If } \quad\left|\frac{I_{\alpha 1}}{I_{\alpha 2}}\right|>1 \quad \text { or } \quad\left|\frac{I_{\beta 1}}{I_{\beta 2}}\right|>1 \quad \text { Fault Internal Circuit } 1 \\
& \text { If } \quad\left|\frac{I_{\alpha 2}}{I_{\alpha 1}}\right|>1 \quad \text { or } \quad\left|\frac{I_{\beta 2}}{I_{\beta 1}}\right|>1 \quad \text { Fault Internal Circuit 2 } \\
& \text { If } \quad\left|\frac{I_{\alpha 1}}{I_{\alpha 2}}\right|=1 \quad \text { or } \quad\left|\frac{I_{\beta 1}}{I_{\beta 2}}\right|=1 \quad \text { Fault External }
\end{aligned}
$$

g. The protection technique should be able to classify the faulted phase for single-phase-to-ground faults. In the case of single-phase-to-ground faults, two of the modal components that include the faulted phase should have almost the same amplitude and the other modal component should be zero, as follows:

$$
\begin{array}{ll}
\left|\frac{\left|I_{\alpha}\right|}{\left|I_{\gamma}\right|}-1\right|<\epsilon & \Rightarrow \text { AG fault } \\
\left|\frac{\left|I_{\alpha}\right|+\left|I_{\beta}\right|}{\left|I_{\gamma}\right|}-1\right|<\epsilon & \Rightarrow \text { BG fault } \\
\left|\frac{\left|I_{\alpha}\right|+\left|I_{\beta}\right|}{\left|I_{\gamma}\right|}-1\right|<\epsilon & \Rightarrow \text { CG fault }
\end{array}
$$

The algorithm will continue to determine the faulted phases involved in a multiple-phase fault. In the case of line to line faults, the criteria are as given in (22)-(24):

$$
\begin{array}{ll}
|| I_{\alpha}|+| I_{\beta}|-| I_{\gamma}||<\sigma & \Rightarrow \text { AB fault } \\
|| I_{\beta}|+| I_{\gamma}|-| I_{\alpha}||<\sigma & \Rightarrow \text { AC fault } \\
|| I_{\beta}|-| I_{\gamma}||<\sigma & \Rightarrow \text { BC fault }
\end{array}
$$

In the case of double line to ground faults, the criteria are as given in (25)-(27):

$$
\begin{array}{ll}
|| I_{\gamma}\left|-\left(\left|I_{\alpha}\right|+\left|I_{\beta}\right|\right)\right|<\delta & \Rightarrow \text { ABG fault } \\
\left|\left(\left|I_{\alpha}\right|+\left|I_{0}\right|\right)-\left(\left|I_{\beta}\right|+\left|I_{\gamma}\right|\right)\right|<\delta & \Rightarrow \text { ACG fault } \\
\left|\left(\left|I_{\gamma}\right|+\left|I_{0}\right|\right)-\left(\left|I_{\alpha}\right|+\left|I_{\beta}\right|\right)\right|<\delta & \Rightarrow \text { BCG fault }
\end{array}
$$

h. Determining the fault Classification where the fault classification was divided into 2 categories 
ground and unground. The current approach had zero given threshold or less equal to zero than the disruption of unground fault, otherwise if the current $I_{0}$ is greater than the specified threshold limit, it would be the ground fault.

The unground fault was the line to line fault, while the threshold limit was given for termination criteria $\sigma=0: 02$, while the ground was divided into 2 , which were line to ground fault with the given threshold $\varepsilon=0: 03$ and the line to line to ground fault with the given threshold $\delta=0: 05$ for the termination criteria [34], as shown in Figure 2 that illustrates the proposed fault-type classification algorithm that uses the modal components of the current signals.

\section{SIMULATION RESULTS AND DISCUSSIONS}

The system was connected with the sources at each end, as shown in Figure 2. This system was simulated using PSCAD/EMTD. For the case study, the simulation was modelled on a $230 \mathrm{kV}$ double circuit transmission line, which was $200 \mathrm{~km}$ in length.

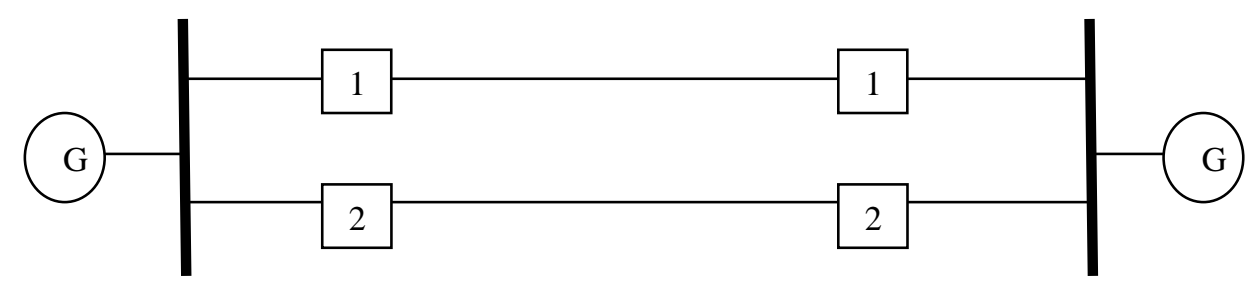

Figure 2. One line diagram of the simulated transmission system

Transmission data:

Sequence Impedance ohm $/ \mathrm{km}$.

Transmission Line $Z_{1}=Z_{2}=0.03574+\mathrm{j} 0.5776 \mathrm{Z}_{0}=0.36315+\mathrm{j} 1.32 .647$

Fault Starting

0.15 Second

Fault resistance $\left(R_{f}\right)$

$=0.22$ second Duration in fault $=$

Fault Inception Angle $=0,15,30,45,60,90,120$ and 150 degree

Source $\mathrm{A}$ and $\mathrm{B} \mathrm{Z}_{1}=\mathrm{Z}_{2}=\mathrm{Z}_{0} \quad=9.1859+\mathrm{j} 52.093 \mathrm{Ohm}$

Type Conductor $=$ Chukar, diameter $=1.602$ inch,

$D_{s}=0.0524 \mathrm{ft}=0.0162763 \mathrm{~m}$

The results of the calculations took into account the position of the tower and distance between the conductors. The conductor types used for this simulation were obtained using the propagation velocity $=\frac{1}{\sqrt{L C}}=299863.4379 \mathrm{~km} /$ second.

\subsection{Internal Fault}

Table 1 shows the results of various internal fault variations with fault resistance $=0.001 \mathrm{Ohm}$ and the fault inception angle of 0 degrees at various distances of errors. The biggest fault currentoccurred on the line to ground fault (AG) at a distance of $25 \mathrm{~km}$ with a current of $2.8953 \mathrm{kA}$. The selected threshold line to ground for fault $\varepsilon=0.03$ from the simulation results showed that the fault threshold line to ground (AG) was $\varepsilon=0.0237$ which is smaller than the threshold $(\varepsilon)$ set.

Also shown in Table $2 I_{\alpha 1} / I_{\alpha 2}$ and $I_{\beta 1} / I_{\beta 2}$ on all types of faults that are greater than 1 , which indicate that the fault was an internal fault in circuit 1 , WTC of the aerial mode and ground mode are shown in Figure 3 The Clarke's transformation and the mother wavelet Db8 obtained the biggest percentage error in fault location, about $0.4649 \%$, at the three phase disorder $(\mathrm{AB})$ which had a distance of $75 \mathrm{~km}$ and the WTC of the aerial mode and ground mode are shown in Figure 4 while the smallest percentage error in fault location was about $0.0750 \%$, in line to line (AC) at a distance of $100 \mathrm{~km}$. This indicates that the proposed algorithm for fault classification is accurate and precise. 
Table 1. The obtained result for different faults using the Clarke's Transformation and mother wavelet Db8

\begin{tabular}{|c|c|c|c|c|c|c|c|}
\hline Fault & $\mathrm{AG}$ & BG & $\mathrm{AB}$ & $\mathrm{AC}$ & $\mathrm{ABG}$ & ACG & $\mathrm{ABC}$ \\
\hline Distance $(\mathrm{km})$ & 25 & 50 & 75 & 100 & 125 & 150 & 175 \\
\hline$R_{f}(\mathrm{Ohm})$ & 0.001 & 0.001 & 0.001 & 0.001 & 0.001 & 0.001 & 0.001 \\
\hline Fault Inception Angle & 0 & 0 & 0 & 0 & 0 & 0 & 0 \\
\hline$I_{a}(\mathrm{kA})$ & 2.8953 & 0.5330 & -2.3266 & 2.3941 & -1.6213 & 1.5088 & 1.3156 \\
\hline$I_{b}(\mathrm{kA})$ & 0.5543 & 3.3782 & 2.6240 & -0.4809 & 2.3185 & -0.5580 & 1.7432 \\
\hline$I_{c}(\mathrm{kA})$ & 0.5590 & -0.5358 & 0.4682 & 2.1064 & -0.5121 & -1.9317 & -1.8289 \\
\hline$I_{\alpha 1} \quad(\mathrm{kA})$ & 1.9146 & -0.8914 & -2.3264 & 2.3938 & -1.6364 & 1.6941 & 1.3141 \\
\hline$I_{\beta 1} \quad(\mathrm{kA})$ & 0.4722 & 2.0446 & 1.6739 & 1.0421 & 1.4762 & 0.9851 & 1.8197 \\
\hline$I_{\gamma 1} \quad(\mathrm{kA})$ & 1.9612 & 2.9020 & 4.0132 & -1.3441 & 3.0248 & 1.2014 & 2.3410 \\
\hline$I_{o}(\mathrm{kA})$ & 1.0492 & 1.1841 & 0.00178 & 0.00198 & 0.5472 & -0.4538 & 0.0321 \\
\hline$I_{\alpha 2} \quad(\mathrm{kA})$ & -0.5674 & 0.4403 & 0.6615 & -0.5065 & -0.6707 & 0.7786 & -0.8424 \\
\hline$I_{\beta 2} \quad(\mathrm{kA})$ & -0.3011 & -0.4040 & 0.4453 & 0.5377 & 0.6624 & 0.4012 & 0.9667 \\
\hline$I_{\alpha 1} / I_{\alpha 2}$ & -3.3743 & -2.0245 & -3.5168 & -4.7267 & -2.4391 & 2.1758 & -1.5599 \\
\hline$I_{\beta 1} / I_{\beta 2}$ & -1.5682 & -5.0609 & -3.5212 & 1.9381 & -1.9417 & 2.1708 & 1.8823 \\
\hline $\begin{array}{l}\text { Calculate point of } \\
\text { Fault }(\mathrm{km})\end{array}$ & 25.765 & 49.103 & 75.930 & 99.850 & 123.995 & 150.98 & 174.235 \\
\hline$\%$ Error & 0.3825 & -0.4994 & 0.4649 & -0.0750 & -0.5024 & 0.4994 & 0.3825 \\
\hline
\end{tabular}

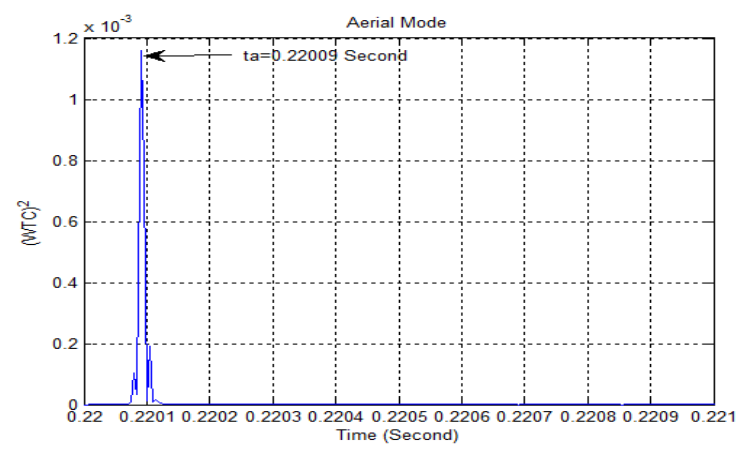

(a)

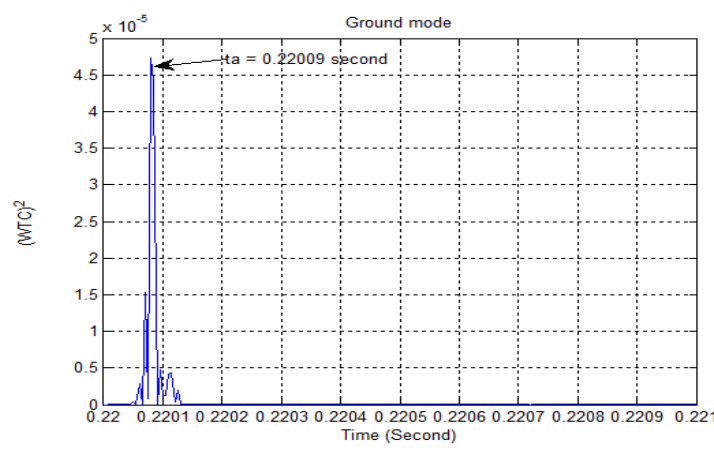

(b)

Figure 3. Line to line fault (AG) circuit 1 from 25 from bus A, (a) Aerial mode for wavelet mother Db8, (b) For ground mode for wavelet mother Db8.

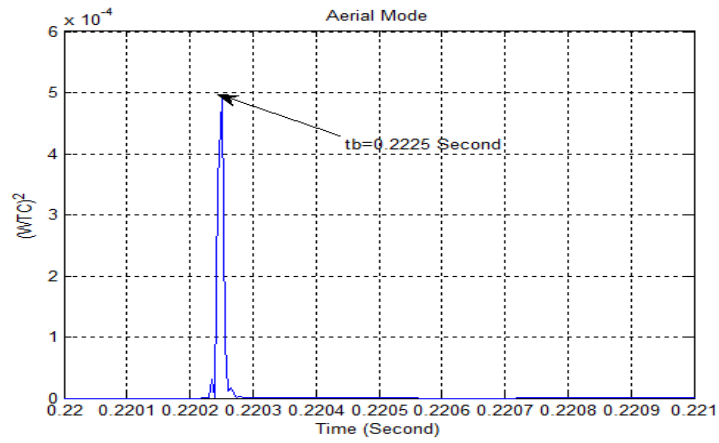

(a)

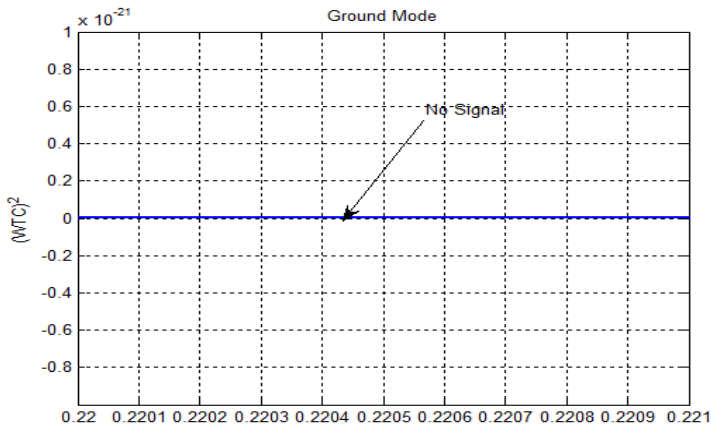

(b)

Figure 4. Line to ground fault (AB) circuit 1 from 75 from bus A, (a) Aerial mode for wavelet Mother Db8, (b) For ground mode for wavelet mother Db8

\subsection{Influence of Fault Resistance}

Table 2 shows the effects of variations in the resistance of $25 \mathrm{ohms}$ and $50 \mathrm{ohms}$ with fault inception angle at 15 and 45 degrees with varying distances. The simulation showed that when the resistance was increased, the fault current would drop, where the biggest fault current occurred in line to ground (BG) at a distance of $50 \mathrm{~km}$ with a fault resistance of $25 \mathrm{ohms}$. 
Table 2 shows the effects of variations in the resistance of $25 \mathrm{ohms}$ and $50 \mathrm{ohms}$ with fault inception angle at 15 and 45 degrees with varying distances. The simulation showed that when the resistance was increased, the fault current would drop, where the biggest fault current occurred in line to ground (BG) at a distance of $50 \mathrm{~km}$ with a fault resistance of $25 \mathrm{ohms}$. The fault inception at the angle of 15 degrees was $I_{b}=2.2829 \mathrm{kA}$ and the threshold obtained at $\varepsilon=0.00056$ was smaller than the threshold set $\varepsilon=0.03$. When using the mother wavelet $\mathrm{Db} 8$, the percentage error in the fault location was ranged between 0.4-0.5\%, as shown in Table 3. $I_{\alpha 1} / I_{\alpha 2}$ and $I_{\beta 1} / I_{\beta 2}$ varied from 2.5-8, indicating that the fault was internal to circuit 1

Table 2. Result for different resistance faults based on mother wavelet Db8

\begin{tabular}{|c|c|c|c|c|c|c|c|c|}
\hline Fault & BG & & $\mathrm{AB}$ & & $\mathrm{ACG}$ & & $\mathrm{ABC}$ & \\
\hline Distance $(\mathrm{km})$ & 50 & & 75 & & 125 & & 150 & \\
\hline Fault Inception Angle & 15 & & 15 & & 45 & & 45 & \\
\hline Fault Resistance $R_{f}(\mathrm{Ohm})$ & 25 & 50 & 25 & 50 & 25 & 50 & 25 & 50 \\
\hline$I_{b}(\mathrm{kA})$ & -2.2829 & 1.7328 & 2.1951 & 1.7831 & 0.2377 & 0.2190 & 1.8558 & -1.576 \\
\hline$I_{c}(\mathrm{kA})$ & 0.2450 & -0.2375 & 0.1574 & 0.1574 & -1.4154 & -1.1325 & -1.7960 & 1.5244 \\
\hline$I_{\alpha 1} \quad(\mathrm{kA})$ & -0.9056 & -0.7183 & -2.0771 & -1.6669 & 1.2068 & -1.0092 & -1.5970 & 1.4178 \\
\hline$I_{\gamma 1} \quad(\mathrm{kA})$ & 2.1335 & -1.6427 & 3.4108 & 2.7635 & -0.7128 & 0.6131 & 2.5946 & 2.2336 \\
\hline$I_{o}(\mathrm{kA})$ & 0.7745 & 0.5730 & 0 & 0 & 0.4156 & -0.2974 & 0 & 0 \\
\hline$I_{\alpha 2} \quad(\mathrm{kA})$ & 0.2046 & -0.2253 & 0.4731 & 0.4566 & 0.4330 & 0.3544 & 0.6073 & 0.5599 \\
\hline$I_{\beta 2} \quad(\mathrm{kA})$ & 0.2581 & -0.2329 & 0.3001 & 0.2724 & 0.4203 & 0.3759 & 0.5707 & 0.5207 \\
\hline$I_{\alpha 1} / I_{\alpha 2}$ & -4.4262 & 3.1882 & 4.3904 & 3.6507 & 2.7871 & 2.8476 & 2.6296 & 2.5322 \\
\hline$I_{\beta 1} / I_{\beta 2}$ & 8.2661 & 3.9944 & 11.3655 & 4.0264 & 2.1970 & 2.0074 & 3.2874 & 2.1773 \\
\hline
\end{tabular}

\subsection{Influence of Fault Inception.}

As shown in Table 3, the simulations showed the effect on the variation of fault inception angle, ranging from 30 degrees to 150 degrees, with variations in fault resistance of $75 \mathrm{ohm}$ and $100 \mathrm{ohm}$ in the various types of fault and fault distance. Meanwhile, the threshold obtained in line to line ground disturbance $(\mathrm{BCG})$ at a fault distance of $75 \mathrm{~km}$, fault resistance $75 \mathrm{ohm}$ and fault inception angle 75 degrees was $\delta=0.0851$; greater than the threshold set on the fault line to line to the ground of $\delta=0.05$, as it was faulted to the ground. The fault line to line (AC) at a fault distance of $125 \mathrm{~km}$, fault resistance of $100 \mathrm{ohms}$ and fault inception angle of 30 degrees obtained a threshold of $\sigma=0.0017$, smaller than the threshold set of $\sigma=0.02$. Table 3 also shows that if the fault inception angle was enlarged, then the fault current would increase, except for fault three-phase (ABC), which resulted with $I_{\alpha 1} / I_{\alpha 2}$ and $I_{\beta 1} / I_{\beta 2}$, between 1.2-3, indicating that the fault was internal fault circuit 1 . Meanwhile, the percentage error in fault location was obtained around $0.2-0.5 \%$ when using the mother wavelet $\mathrm{Db} 4$. The fault classification algorithms show that the proposed algorithm is correct and responsive.

Table 3. The obtained result for different Fault Inception Angle based on mother wavelet

\begin{tabular}{|c|c|c|c|c|c|c|c|c|}
\hline Fault & $\mathrm{AG}$ & & $\mathrm{AC}$ & & BCG & & $\mathrm{ABC}$ & \\
\hline Distance $(\mathrm{km})$ & 150 & & 125 & & 75 & & 50 & \\
\hline Fault Inception Angle & 60 & 75 & 30 & 45 & 75 & 90 & 120 & 150 \\
\hline$I_{b}(\mathrm{kA})$ & 0.3496 & 0.4948 & 0.0639 & 0.1791 & 1.4682 & 1.5235 & 2.1835 & -1.9497 \\
\hline$I_{c}(\mathrm{kA})$ & 0.4069 & 0.5048 & 0.9368 & 1.0783 & 1.4639 & 1.5305 & 2.1482 & 2.0210 \\
\hline$I_{\alpha 1}(\mathrm{kA})$ & 0.6723 & 0.8005 & 0.8963 & 0.9292 & 0.7293 & -0.8503 & 2.2589 & 2.0813 \\
\hline$I_{\gamma 1}(\mathrm{kA})$ & 0.7216 & 0,7418 & -0.3217 & -0.2940 & 1.7983 & 1.9133 & 3.2379 & 2.8001 \\
\hline$I_{o}(\mathrm{kA})$ & 0.1957 & 0.1829 & 0 & 0 & 0.3223 & 0.3496 & 0 & 0 \\
\hline$I_{\alpha 2} \quad(\mathrm{kA})$ & 0.4196 & 0.5677 & 0.2908 & 0.3547 & 0.4812 & 0.6391 & 0.9405 & 1.0646 \\
\hline$I_{\beta 2} \quad(\mathrm{kA})$ & 0.2260 & 0.3706 & 0.2374 & 0.3752 & 0.5994 & 0.7006 & 1.0632 & $1.1361^{`}$ \\
\hline$I_{\alpha 1} / I_{\alpha 2}$ & 1.6002 & 1.4100 & 3.0822 & 2.6197 & 1.5165 & -1.3305 & 2.4018 & 1.9555 \\
\hline$I_{\beta 1} / I_{\beta 2}$ & 1.4187 & 1.2849 & 2.4276 & 1.9144 & 2.4631 & 2.2247 & 2.2517 & 1.7363 \\
\hline
\end{tabular}




\subsection{Percentage Error in Fault Location for different Types of Mother Wavelet}

Table 4 shows the simulation error in determining the fault location when using various types of mother wavelet on the interference resistance of $100 \mathrm{ohms}$, fault inception angle of 0 degrees and a distance of interference, varied from $25 \mathrm{~km}-190 \mathrm{~km}$. The fault location estimation error was formulated as follows:

$$
\text { Error } \%=\frac{\text { Fault Simulated Distance-Real fault Distance }}{\text { Total lenght of line }} \times 100 \%
$$

From Table 4 it can be seen that the smallest average error was shown by the mother wavelet DB4, while mother wavelets Sym 4, Coil 4 and Db8 have a variation around 0.2-05\%

Table 4. Percentage error in fault location for different types of Mother Wavelet from Circuit 1,

\begin{tabular}{|c|c|c|c|c|c|c|c|c|c|}
\hline \multirow{2}{*}{$\begin{array}{l}\text { Type Of } \\
\text { Fault }\end{array}$} & \multirow{2}{*}{$\begin{array}{c}\text { Actual } \\
\text { Point } \\
\text { Fault } \\
(\mathrm{km})\end{array}$} & \multicolumn{2}{|c|}{ Db4 } & \multicolumn{2}{|c|}{ Coif4 } & \multicolumn{2}{|c|}{ Syms4 } & \multicolumn{2}{|c|}{ DB8 } \\
\hline & & $\begin{array}{l}\text { Calculate } \\
\text { point of } \\
\text { Fault }(\mathrm{km})\end{array}$ & $\begin{array}{l}\text { Error }= \\
(\mathrm{x}-\mathrm{d}) / \mathrm{L} \\
* 100 \%\end{array}$ & $\begin{array}{l}\text { Calculate } \\
\text { point of } \\
\text { Fault }(\mathrm{km})\end{array}$ & $\begin{array}{l}\text { Error }= \\
(\mathrm{x}-\mathrm{d}) / \mathrm{L} \\
* 100 \%\end{array}$ & $\begin{array}{l}\text { Calculate } \\
\text { point of } \\
\text { Fault }(\mathrm{km})\end{array}$ & $\begin{array}{l}\text { Error }= \\
(\mathrm{x}-\mathrm{d}) / \mathrm{L} \\
* 100 \%\end{array}$ & $\begin{array}{l}\text { Calculate } \\
\text { point of } \\
\text { Fault }(\mathrm{km})\end{array}$ & $\begin{array}{l}\text { Error }= \\
(\mathrm{x}-\mathrm{d}) / \mathrm{L} \\
* 100 \%\end{array}$ \\
\hline & 25 & 25.0151 & 0.0076 & 25.7650 & 0.3852 & 25.3150 & 0.1575 & 25.7650 & 0.3825 \\
\hline & 50 & 49.7601 & -0.1949 & 49.6110 & -0.4949 & 49.0103 & -0.4949 & 49.0103 & -0.4949 \\
\hline & 75 & 75.2550 & 0.1275 & 75.8549 & 0.4274 & 76.0080 & 0.5024 & 76.0048 & 0.5024 \\
\hline LG & 125 & 124.745 & -0.1275 & 124.142 & -0.4274 & 123.995 & -0.5024 & 123.995 & -.0 .5024 \\
\hline \multirow[t]{6}{*}{$(\mathrm{AG})$} & 150 & 150.239 & 0.1949 & 150.389 & 0.4949 & 150.989 & 0.4949 & 150.988 & 0.4949 \\
\hline & 175 & 174.985 & -0.0076 & 174.350 & -0.3852 & 174.695 & -0.1575 & 174.235 & -0.3825 \\
\hline & 190 & 189.981 & 0.0091 & 189.082 & -0.4590 & 189.750 & -0.1216 & 189.232 & -0.3840 \\
\hline & 25 & 24.5650 & -0.2174 & 24.1153 & -0.4423 & 25.4651 & 0.2325 & 25.9150 & 0.4575 \\
\hline & 50 & 49.7601 & -0.1199 & 49.1603 & -0.4199 & 48.8603 & -0.5695 & 48.9350 & -0.5323 \\
\hline & 75 & 75.4050 & 0.2204 & 75.8549 & 0.4274 & 76.0080 & 0.5024 & 76.0048 & 0.5024 \\
\hline LL & 125 & 124.590 & -0.2204 & 124.142 & -0.4274 & 123.995 & -0.5024 & 123.995 & -.0 .5024 \\
\hline \multirow{6}{*}{$(\mathrm{AB})$} & 150 & 150.239 & 0.1199 & 150.841 & 0.4199 & 151.139 & 0.5698 & 151.065 & 0.5323 \\
\hline & 175 & 175.435 & 0.2174 & 175.885 & 0.4423 & 174.535 & -0.2325 & 174.085 & -0.4575 \\
\hline & 190 & 190.432 & 0.2159 & 190.232 & -0.3840 & 189.680 & -0.1591 & 189.150 & -0.4215 \\
\hline & 25 & 25.0151 & 0.0076 & 25.0151 & 0.0076 & 25.0151 & 0.0076 & 25.6150 & 0.3075 \\
\hline & 50 & 49.7520 & -0.1237 & 49.3120 & -0.3449 & 49.1610 & -0.4199 & 50.8849 & -0.4425 \\
\hline & 75 & 75.6290 & 0.3150 & 75.8849 & 0.4424 & 75.8540 & 0.4274 & 76.0048 & 0.5024 \\
\hline LLG & 125 & 124.371 & -0.3150 & 124.161 & -0.4224 & 124.145 & -0.4274 & 123.995 & -.0 .5024 \\
\hline \multirow[t]{6}{*}{ (BCG) } & 150 & 150.241 & 0.1237 & 150.691 & 0.3449 & 150.839 & 0.4199 & 149.115 & 0.4425 \\
\hline & 175 & 174.985 & -0.0076 & 174.985 & 0.0076 & 174.985 & -0.0076 & 174.385 & -0.3075 \\
\hline & 190 & 190.282 & 0.1409 & 189.682 & -0.1591 & 189.982 & -0.0091 & 189.240 & -0.3765 \\
\hline & 25 & 25.0151 & 0.0076 & 25.3150 & 0.1575 & 25.6150 & 0.3075 & 25.9890 & 0.4950 \\
\hline & 50 & 49.4600 & -0.2699 & 49.0103 & -0.4949 & 48.8310 & -0.5848 & 49.0103 & -0.4949 \\
\hline & 75 & 75.4050 & 0.2025 & 76.0048 & 0.5024 & 76.0080 & 0.5024 & 76.1090 & 0.5549 \\
\hline \multirow{4}{*}{$\begin{array}{c}\text { LLL } \\
(\mathrm{ABC})\end{array}$} & 125 & 124.595 & -0.2025 & 123.995 & -0.5024 & 123.995 & -0.5024 & 123.901 & -.0 .5549 \\
\hline & 150 & 150.540 & 0.2699 & 150.989 & 0.4949 & 151.169 & 0.5848 & 150.988 & 0.4949 \\
\hline & 175 & 174.985 & -0.0076 & 174.685 & 0.1575 & 174.395 & -0.3075 & 174.020 & -0.4950 \\
\hline & 190 & 190.582 & 0.2909 & 189.532 & -0.2340 & 189.530 & -0.2340 & 189.090 & -0.4515 \\
\hline
\end{tabular}

\subsection{External Fault}

Table 5 shows that $I_{\alpha 1} / I_{\alpha 2}=1$ and $I_{\beta 1} / I_{\beta 2}=1$ in various types of fault, with a fault resistance of 100 and $0.001 \mathrm{Ohms}$, and fault inception angle of 0 and 60 degrees, which shows that the disturbance was an external fault. The largest fault current was found in the type of fault Bus B Line to line (AB) with fault resistance $0.0001 \mathrm{Ohm}$, fault inception angle at 60 degrees, and at $1.4344 \mathrm{kA}$.

\subsection{Determining Fault Location using Karenbauer's Transformation}

Table 6 shows the percentage error in the calculation of fault location by using another method, which is Karenbaur's Transformation, for comparison when using Clarke's transformation (Table 1). It turned out that the results obtained by both methods in determining the fault location percentage error were similar. The only difference between $I_{\alpha 1} / I_{\alpha 2}$ and $I_{\beta 1} / I_{\beta 2}$ in, Table 1 was that the transformations achieved $I_{\alpha 1} / I_{\alpha 2}=-3,3743$ and $I_{\beta 1} / I_{\beta 2}=-1.5682$ respectively, in the type of line to ground disturbance (AG) at fault distance $25 \mathrm{~km}$, fault inception angle 0 degrees and fault resistance $0.001 \mathrm{ohm}$, whereas Table 6 shows type of fault at $I_{\alpha 1} / I_{\alpha 2}=3.6515$ and $I_{\beta 1} / I_{\beta 2}=2.4853$. 
Table 5. The obtained result for different external fault

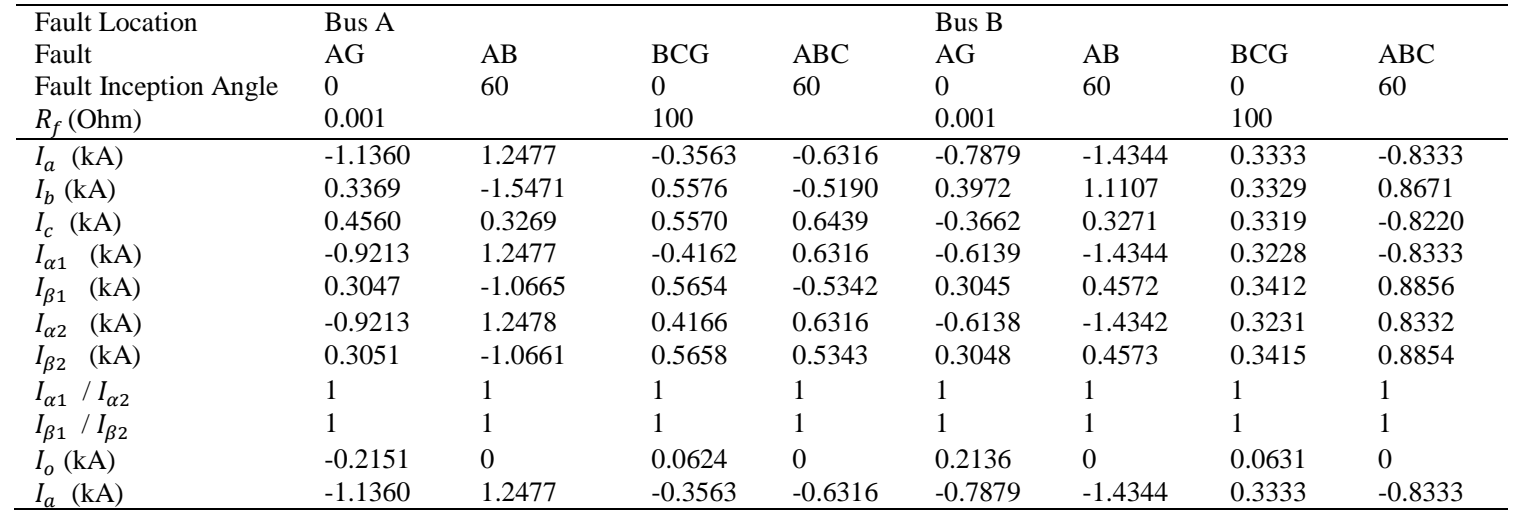

Table 6. The obtained result for different faults based on Karenbauer transformation and mother wavelet Db8

\begin{tabular}{|c|c|c|c|c|c|c|c|}
\hline Fault & $\overline{A G}$ & BG & $\mathrm{AB}$ & $\mathrm{AC}$ & $\mathrm{ABG}$ & $\mathrm{ACG}$ & $\mathrm{ABC}$ \\
\hline Distance $(\mathrm{km})$ & 25 & 50 & 75 & 100 & 125 & 150 & 175 \\
\hline Fault Inception Angle & 0 & 0 & 0 & 0 & 0 & 0 & 0 \\
\hline $\mathrm{Ib}(\mathrm{kA})$ & 0.5543 & 3.3782 & 2.6240 & -0.4809 & 2.3185 & -0.5580 & 1.7432 \\
\hline Ic $(\mathrm{kA})$ & 0.5590 & -0.5358 & 0.4682 & 2.1064 & -0.5121 & -1.9317 & -1.8289 \\
\hline$I_{\alpha 1}(\mathrm{kA})$ & -1.0604 & -1.0156 & -1.6500 & 0.8938 & -1.2098 & 0.6492 & -0.9158 \\
\hline$I_{\alpha 2} \quad(\mathrm{kA})$ & -0.2904 & 0.2989 & -0.3918 & -0.2586 & 0.2967 & 0.3248 & 0.5674 \\
\hline$I_{\beta 2} \quad(\mathrm{kA})$ & 0.3505 & 0.1752 & -0.2992 & -0.3757 & 0.3797 & 0.4649 & 0.5864 \\
\hline$I_{\alpha 1} / I_{\alpha 2}$ & 3.6515 & -3.3978 & 4.2133 & -3.4563 & -4.0776 & 1.9988 & -1.6140 \\
\hline$I_{\beta 1} / I_{\beta 2}$ & 2.4853 & 1.5862 & 2.2603 & -3.9925 & -1.1673 & 2.3778 & 1.6025 \\
\hline Io $(\mathrm{kA})$ & 1.0422 & 1.1841 & 0.0179 & 0.0198 & 0.5472 & -0.4538 & 0.0321 \\
\hline $\begin{array}{l}\text { Calculate point of } \\
\text { Fault }(\mathrm{km})\end{array}$ & 25.765 & 49.103 & 75.930 & 99.850 & 123.995 & 150.98 & 174.235 \\
\hline
\end{tabular}

\section{CONCLUSION}

The application of parallel transmission lines requires a more special consideration in comparison with the single transmission line, due to the effect of mutual coupling method. To overcome this problem, a new method was proposed, by using the Current alpha and beta (Current mode) from the Clarke's transformation to convert the signal. Then, discrete wavelet transform $(D W T)$ is used to obtain wavelet transform coefficients $(W T C)^{2}$, to determine the current time when the fault amplitude values (WTC ${ }^{2}$ would reach a maximum point, to determine the fault location distance. This paper also proposed algorithm fault classification by using Clarke's transformation. The simulation results showed that the results were accurate, which were also compared against the results obtained by using the Karenbauer's transformation.

\section{ACKNOWLEDGEMENTS}

The authors would like to express their gratitude to Universiti Teknologi Malaysia, The State Polytechnic of Ujung Pandang, PT. PLN (Persero) of South Sulawesi and the Government of South Sulawesi Indonesia for providing the financial and technical support for this research.

\section{REFERENCES}

[1] IEEE Guide for Determining Fault Location on AC Transmission and Distribution Lines, IEEE Std C37.114, (2004).

[2] J. Song and Y.G. Suonan, "An accurate fault location algorithm for parallel transmission lines using one terminal data," Elect Power Energy Syst, 31, pp.124-129, 2009.

[3] J. Izykowski, al., et., "Locating faults in power transmission lines under availability of complete measurements at one end, " Proc Inst Elect Eng Gen Transm Distrib, 151, pp. 268-273, 2004.

[4] S.H. Kang, al., et., "A fault location algorithm based on circuit analysis for un transposed parallel transmission lines," IEEE Trans Power Del, 24, pp. 1850-1856, 2009.

[5] J. Suonan, al., et., "Time domain fault location for parallel transmission lines using unsynchronized currents," Elect 
Power Energy Syst, 28, pp. 253-260, 2006.

[6] J.Tang, al., et., "Traveling-Wave-Based Fault Location in Electrical Distribution Systems with Digital Simulations," TELKOMNIKA (Telecommunication Computing Electronics and Control). 12(2),pp 297-309, 2014

[7] A. Sharafi, al., et., "Non communication protection of parallel transmission lines using breakers open switching travelling waves," IET Gener Transm. Distrib, 6, pp.88-98, 2012.

[8] Y.J. Ahn, al., et., "An accurate fault location algorithm for double-circuit transmission systems", In Power engineering society summer meeting, Seattle, “Washington, USA, IEEE, pp.1344-1349, 2000.

[9] H. Jung, al., et., "Novel technique for fault location estimation on parallel transmission lines using wavelet," Int $J$ Electr Power Energy Syst, 29, pp.76-82, 2007.

[10] B. Polajzer, al., et., "Detection of voltage sources based on instantaneous voltage and current vectors and orthogonal clarke's transformation," IET Gener Transm Distrib, 2, pp.219-226, 2008.

[11] B. Noshad, al., et., "A new algorithm based on Clarke's Transform and Discrete Wavelet Transform for the differential protection of three-phase power transformers considering the ultra-saturation phenomenon," Electric Power Systems Research, 110, pp.9-24, 2014.

[12] B. SouhaS.R., "Adaptive Speech Compression based on Discrete Wave Atoms Transform," International Journal of Electrical and Computer Engineering (IJECE), 6 (5), pp. 2150-2157.

[13] S. Patthi, al., et., "Neutral current wave shape analysis using wavelet for diagnosis of winding insulationn of a transformer," Turk J Elec Eng \& Comp Sci, 20, pp. 835-841, 2012.

[14] P. Chandrasekar and V. Kamaraj, "Detection and classification of power quality disturbance waveform Using MRA based modified wavelet transfrom and neural networks," Journal of Electrical Engineering, 61(4), pp.235-240, 2010.

[15] Y.Menchafou1, al., et., "Extension of the Accurate Voltage-Sag Fault Location Method in Electrical Power," J. Electrical Systems, 12(1), pp.33-34, 2016.

[16] Maknimg P, al., et., "Fault diagnosis in transmission lines using wavelet transform analysis," IEEE/PES Transmission and Distribution Conference and Exhibition, IEEE. pp.2246-2250, 2002

[17] PSCAD/EMTDC User's Manual. Manitoba HVDC Research Center. Winnipeg MB. Canada, 2001.

[18] Mario, M. C. al., et., "Three-phase adaptive frequency measurement based on Clarke's Transformation," IEEE Trans. on Power Delivery, 21 (3), pp. 1101-1105 (2006)

[19] O.F. Alfredo, al., et., "Three-phase adaptive frequency measurement based on Clarke's Transformation," IEEE Trans. on Power Delivery, 21(3), pp. 1101-1105, 2006.

[20] G. Hosemann and H.M. Steigerwald, "Modal saturation detector for digital differential protection," IEEE Trans on Power Deliv, 8(3), pp.933-940, 1993.

[21] M. Saini, al., et., "An accurate fault detection and location on transmission line using wavelet based on Clarke's transformation," Przeglad Elektrotechniczny 90(11), pp. 156-161, 2014.

[22] P. Bunnon, "Electricity Peak Load Demand using De-noising Wavelet Transform integrated with Neural Network Methods," International Journal of Electrical and Computer Engineering (IJECE), 6 (1), pp. 12 20, 2016

[23] J. Sajad, al., et., "Classification of power quality disturbances using S-transform and TT-transform based on the artificial neural network”, Turk J Elec Eng \& Comp Sci, 21, pp.1528 - 1538, 2013.

[24] F. Ravas, al., et., "Application of wavelet transformation in defectos copy of power steam generator," Journal of Electrical Engineering, 55 (10), PP. 101-104, 2004.

[25] B. Alberto, al., et., "Continuous wavelet transform for fault location in distribution power networks, definition of mother wavelet inferred from fault originated transient," IEEE Trans on Power Delivery, 23, PP. 380-389, 2008

[26] A. Sedighi, "Classification of Transient Phenomena In Distribution System Using wavelet Transform," Journal of Electrical Engineering, 65(3), 144-150, 2014

[27] D. Zhang and J. Li., "An Image Registration Method Based on Wavelet Transform and Ant Colony Optimization," TELKOMNIKA (Telecommunication Computing Electronics and Control). 13(2),pp 304-313, 2015

[28] F. Janicek, al., et., " A New Protection Relay Based on Fault Transient Analysis Using wavelet Transform," Journal of Electrical Engineering, 58 (5), PP. 271-278, 2007.

[29] K. Saravanababu, al., et., "Transmission Line Faults Detection, Classification, and Location Using Discrete Wavelet Transform," International Conference on Power, Energy and Control (ICPEC), Rangalatchum Dindigul. IEEE, PP. 233-238, 2013.

[30] D. Chandra, al., et., "A Wavelet multiresolution analysis for location of fault on transmission line," Electrical Power and Energy System, 25, PP. 59-69, 2003.

[31] H. Eristi and Y. Demir, "Determinant based feature extraction for fault detection and classification for power transmission lines," IET Gener Transm Distrib, 6, pp.968-976, 2012

[32] C. Pothisarn and A. Ngaopitakkul, "Discrete wavelet transform and back propagation neural networks algorithm for fault location on single-circuit transmission line," In: Proceedings of the 2008 IEEE International Conference on Robotics and Biomimetics, Bangkok, Thailand, IEEE,PP. 1613-1618, 2009.

[33] F.H. Magnago, A. Abur, "Fault location using wavelets," IEEE Transactions on Power Delivery, 13(4), pp.1475-1480, 1998.

[34] S. Lin, al., et., "Travelling wave time frequency characteristic based fault location method for transmission lines," IET Gener Transm Distrib, 6, 764-772, 2012. 


\section{BIOGRAPHIES OF AUTHORS}
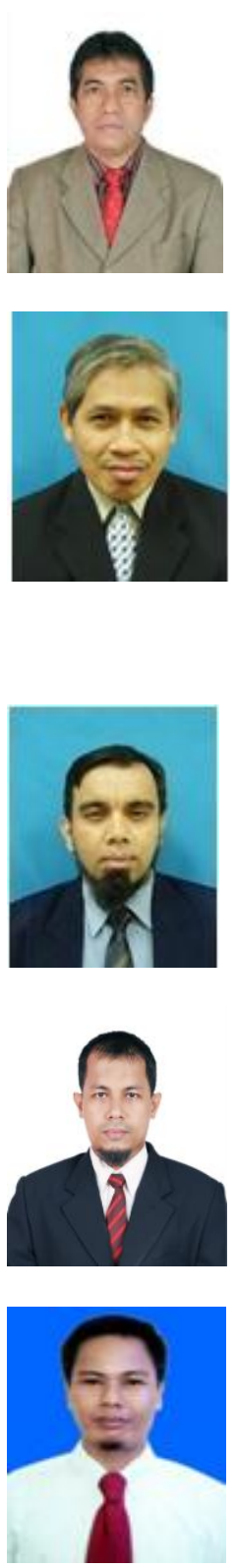

Makmur Saini received his B. Eng. in Electrical Engineering in 1987 from Hasanuddin University and M.Eng Electrical Power in 1993 from Insitut Teknology Bandung Indonesia. Currently, he is an Associate Professor Engineering Department of Mechanical Engineering, Politeknik Negeri Ujung Pandang, Makassar. His research interests include Power System Protection, power system stability, Transmission and Distribution, High Voltage and renewable energy application.

Abdullah Asuhaimi Mohd Zin received the B.Sc. degree from Gadjah Mada University, Indonesia, in 1976, the M.Sc. degree from University of Strathclyde, Strathclyde, U.K. in 1981, and the Ph.D. degree from the University of Manchester Institute of Science and Technology, Manchester, U.K., in 1988. Currently, he is a Professor Engineering Department, Faculty of Electrical Engineering, Universiti Teknologi Malaysia, Johor Bahru. His research interests include power system protection, application of neural network in power system, arcing fault in underground cables, power quality and dynamic equivalent of power systems. Dr. Mohd Zin is a corporate member of The Institution of Engineers, Malaysia (IEM) and a member of the Institute of Electrical Engineers (U.K.). He is a registered Professional Engineer (P. Eng.) in Malaysia and Chartered Engineer (C.Eng.) in the United Kingdom.

Mohd Wazir Mustafa received his B. Eng Degree (1988), M. Sc. (1993) and PhD (1997) from university of Strathclyde. He is currently an Associate Professor and Deputy Dean Graduate Studies and Research at Faculty of Electrical Engineering, Universiti Teknologi Malaysia (UTM), Johor Bahru, Malaysia. He research interest includes power system stability, FACTS and power system distribution automation. He is a member of IEEE.

Ahmad Rizal Sultan received the B.Sc. degree in 1999, the M.Eng Electrical 2006 from Hasanuddin University; Indonesia. Currently, he is an Associate Professor Engineering Department of Electrical Engineering, Politeknik Negeri Ujung Pandang, Makassar. His areas of interests are Power System Grounding Analysis, Power System Protection and Electric installation.

Rusdi Nur received his B.Eng. in Mechanical Engineering in 1999 from Hasanuddin University, Dipl.Eng of Manufacturing Engineering in 2001, and M.Eng of Mechanical Engineering in 2008 from Hasanuddin University Indonesia. Ph.D. degree from Universiti Teknologi Malaysia, Johor, Malaysia, in 2016. Currently, he is an Associate Professor Engineering Department of Mechanical Engineering, Politeknik Negeri Ujung Pandang, Makassar. His research interests include machining process and sustainable manufacturing. 